\title{
Prognostic factors in the occurrence of posttraumatic epilepsy after penetrating head injury suffered during military service
}

\author{
Bizhan Aarabi, M.D., Musa Taghipour, M.D., Ali Haghnegahdar, M.D., \\ MAJIDREZA FAROKHI, M.D., AND LlOYd MOBLEY, M.D. \\ Division Of Neurosurgery, University Of Nebraska Medical Center, Omaha, Nebraska; \\ Division of Neurosurgery, Shiraz University of Medical Sciences, Shiraz, Iran
}

In this retrospective study, the authors evaluated confounding risk factors, which are allegedly influential in causing unprovoked posttraumatic epilepsy, in 489 patients from the frontlines of the Iran--Iraq War.

Four hundred eighty-nine patients were followed for 6 to154 months (mean 39.4 months, median 23 months), and important factors precipitating posttraumatic epilepsy were evaluated using uni- and multivariate regression analysis.

One hundred fifty-seven (32\%) of 489 patients became epileptic during the study period. The results of univariate analysis indicated a significant relationship between epilepsy and Glasgow Outcome Scale (GOS) score $\left(\mathrm{X}^{2}=76.49, \mathrm{p}<0.0001, \mathrm{df}=2\right)$, Glasgow Coma Scale score at admission $\left(\mathrm{X}^{2}=19.48, \mathrm{p}<0.0001, \mathrm{df}=3\right)$, motor deficit $\left(\mathrm{X}^{2}=11.79, \mathrm{p}<0.001, \mathrm{df}=1\right)$, mode of injury $\left(X^{2}=10.731, p<0.05\right)$, transventricular injury $\left(X^{2}=6.9, p<0.008, d f=1\right)$, dysphasia $\left(X^{2}=5.3\right.$, $\mathrm{p}<0.02)$, central nervous system infections $\left(X^{2}=5.3, p<0.02\right)$, and early-onset seizures $\left(X^{2}=4.1\right.$, $\mathrm{p}<0.04, \mathrm{df}=1)$. The results of multivariate analysis, on the other hand, indicated that the GOS score and motor deficit were of greater statistical importance $\left(\mathrm{X}^{2}=35.24, \mathrm{p}<0.0001\right.$; and $\mathrm{X}^{2}=7.1, \mathrm{p}<$ 0.07 , respectively). Factors that did have much statistically significant bearing on posttraumatic epilepsy were the projectile type, site of injury on the skull, patient age, number of affected lobes, related hemorrhagic complications, and retained metallic or bone fragments.

Glasgow Outcome Scale score and focal motor neurological deficit are of particular importance in predicting posttraumatic epilepsy after missile head injury.

\footnotetext{
KeY Words • posttraumatic epilepsy • head injury • gunshot wounds • penetrating head injury • epilepsy • outcome • war
}

Each year nearly half a million people are involved in some kind of accidental brain injury, and 80,000 of them require hospitalization due to moderate to severe TBI. ${ }^{13,22}$ Mortality and morbidity as a consequence of TBI are a major public health problem. ${ }^{13}$ Posttraumatic epilepsy is linked to psychosocial disability and is probably a contributing factor to premature death after penetrating head injury. ${ }^{8,21,23,24,27}$ Almost $50 \%$ of victims of penetrating head trauma enrolled in military series become epileptic. ${ }^{1,19,20}$ The exact pathophysiology of PTE after closed or penetrating head injury is not known. Analysis of some evi-

\footnotetext{
Abbreviations used in this paper: $\mathrm{df}=$ degrees of freedom; GCS = Gasgow Coma Scale; GOS = Glasgow Outcome Scale; PTE $=$ posttraumatic epilepsy; $\mathrm{TBI}=$ traumatic brain injury.
}

dence suggests that iron could play a role in the pathogenesis of the seizure focus. ${ }^{9,14,17}$ Recent data indicate that although phenytoin and valproate are capable of reducing the incidence of early posttraumatic seizures, they are incapable of preventing late-onset PTE. ${ }^{12,22,30}$ Many confounding risk factors, such as retained metal fragments, the extent and site of injury, level of consciousness, residual focal deficit, and complications have been studied to pinpoint the importance of each in efforts to clarify the pathophysiological mechanisms of PTE and therefore prophylaxis. ${ }^{2,6,7,16,19,20,28,29}$ In this study we attempted to bring greater clarity to the rank of different confounding variables in a multivariate regression model.

\section{CLINICAL MATERIAL AND METHODS}

From September 1980 to August 1988, 914 patients 
with penetrating head injury were evacuated to the Nemazee and Beheshti Hospitals, both affiliated with the Shiraz University of Medical Sciences in Iran. These two tertiary medical institutions are in Shiraz, the center of Fars Province, which is 400 miles from the line of combat. Five hundred of the 914 patients had already undergone evaluation in one of several base hospitals near the frontline. Triage and resuscitation of the wounded patients were performed in several casualty-clearing stations near Iran's eastern border with Iraq. These patients were airlifted to Shiraz for recuperation and postoperative care. Two hundred seventy-six of these 500 patients underwent secondary exploration in one of the medical centers in Shiraz. Of the 914 patients, 414 underwent their primary examination in Shiraz an average of 49 hours after sustaining a penetrating head injury. These patients were given antibiotics and dexamethasone and, unless specifically indicated, prophylactic anticonvulsant medications were not routinely provided.

After arriving in the emergency room of the Nemazee Hospital, a quick neurological examination was performed by the staff of the Neurosurgical Division, and radiological studies were obtained. The technique of surgical exploration in Shiraz was that reported as used in Vietnam. ${ }^{5}$ The procedure was radical and complete. All visible hematoma and pulped brain with superficial foreign bodies were removed, but the inaccessible deep metal fragments were left intact. The torn dura was repaired, with or without a graft material, and the scalp was closed in a watertight fashion. After exploration, the patients were kept on antibiotics and dexamethasone for a total of 10 days and, when ready, were discharged to rehabilitation centers. No attempt was made to keep the patients on long-term prophylactic medication for posttraumatic seizures.

In this series, 124 patients died, and 301 patients did not undergo long enough follow up or were lost to follow up. Four hundred eighty-nine patients were periodically followed from 6 to 154 months (mean 39.4 months, median 23 months) to check for new-onset seizures and established epilepsy.

All but two patients were male, and the mean age was $21 \pm 5.7$ years.

\section{Type of Projectile and Mode of Injury}

Of the 489 patients followed, $348(71 \%)$ had been injured by shell fragments and $49(10 \%)$ by missiles. The type of projectile could not be determined in 92 patients (19\%). The mode of injury was penetrating in 263 patients (53.8\%), tangential in $128(26.2 \%)$, and perforating in 32 $(6.5 \%)$. The exact mode of injury was not known in 66 patients $(13.5 \%)$.

\section{Site of Injury, Number of Lobes, and Ventricular Involvement}

Sites of injury on the skull were parietal in 210 patients; frontal in 135; frontoparietal in 31; temporal in 29; occipital in 21; parietooccipital in 19; and all other areas in 44 patients. In $77 \%$ of the patients either frontal, parietal, or both regions of the skull were involved. In 229 of the 489 patients there was involvement of one lobe, and in 220 there was involvement of two. Three or more lobes were injured in 36 victims. The number of lobes involved was unknown in four patients. There was no involvement of the ventricular system in 353 patients as compared with 103 patients with ventricular involvement. In 33 patients there was not enough information to identify ventricular involvement.

\section{Glasgow Coma Scale Score and Focal Deficit at Admission}

The admission GCS score was 13 to 15 in 361 patients (73.8\%); 9 to 12 in 68 (13.9\%); 6 to 8 in 39 (7.9\%); and 3 to 5 in $21(4.2 \%)$. In 217 (44.3\%) of 489 patients motor deficits were demonstrated in the form of hemi-, mono-, tri-, para-, or quadriparesis, and 66 patients (13.5\%) suffered from dysphasia.

\section{Postoperative Complications and Retained Fragments}

The hospital course was complicated by central nervous system infection in 41 patients (meningitis in 34; abscess in eight; and fungus cerebri in one) and intracranial hematomas in 43 (intracerebral hematoma in 30; subdural hematoma in 10; epidural hematoma in five; intraventricular hematoma in one; and subdural hygroma in one). Postoperative radiological studies revealed the presence of retained bone fragments in 109 patients $(22.2 \%)$ and retained metallic fragments in $200(40.9 \%)$ patients.

\section{Glasgow Outcome Scale Score}

All 489 cases were followed for at least 6 months, at which time their GOS score was determined. In 175 patients $(35.8 \%)$ the GOS score was 5, and in $287(58.7 \%)$ the GOS score was 4 . Twenty-seven patients $(5.5 \%)$ were left with severe neurological deficit (GOS score of 3). There were no cases of persistent vegetative state (GOS score of 2) in this series.

\section{RESULTS}

One hundred fifty-seven patients became epileptic during the course of study. Onset latency was during the first 6 months after injury in 63 patients; 7 to 12 months in 50; 13 to 24 months in 17; 25 to 48 months in 19; and 49 to 111 months in only eight patients. In $72 \%$ of the patients the first unprovoked seizure occurred during the 1st year, and $95 \%$ occurred within the first 4 years of follow up. Nearly $5 \%$ of the patients became epileptic at 5 and 10 years post discharge. Epilepsy was major motor in 114 patients; partial motor with generalization in 21; atonic in 10; partial motor in seven; and partial complex in five.

\section{Seizure Duration, Frequency, and Persistence}

Seizure duration (time period between first and last seizure) was an average of 36.07 months (median 14 months, range 1-138 months). Seizure duration was unknown in 25 patients. Twenty-four of 157 patients experienced only one late-onset unprovoked seizure during their follow up. In seven patients multiple seizures were separated by a time span of more than 12 months. In 50 patients multiple epileptic attacks occurred at intervals of less than 6 to more than 12 months between episodes. Seventy of 157 patients experienced seizures packed togeth- 
er during a period of less than 6 months. In six patients we could not obtain enough information about seizure frequency. In 126 patients persistent seizures (any seizure during the previous 24 months) were demonstrated during their follow up.

\section{Statistical Analysis}

Univariate analysis of the following variables disclosed significant correlation with the occurrence of posttraumatic epilepsy: GOS score $\left(\mathrm{X}^{2}=76.49, \mathrm{p}<0.0001, \mathrm{df}=2\right)$, GCS score $\left(X^{2}=19.48, p<0.0001, d f=3\right)$, initial motor deficit $\left(\mathrm{X}^{2}=11.79, \mathrm{p}<0.001, \mathrm{df}=1\right)$, mode of injury $\left(X^{2}=10.7, p<0.05, d f=5\right)$, transventricular injury $\left(X^{2}=\right.$ 6.981, $\mathrm{p}<0.008, \mathrm{df}=1)$, residual motor deficit $\left(\mathrm{X}^{2}=\right.$ 5.963, $\mathrm{p}<0.015, \mathrm{df}=1)$, intracranial sepsis $\left(\mathrm{X}^{2}=5.36\right.$, $\mathrm{p}<0.021, \mathrm{df}=1)$, dysphasia $\left(\mathrm{X}^{2}=5.32, \mathrm{p}<0.02, \mathrm{df}=\right.$ $1)$, and early-onset seizures $\left(\mathrm{X}^{2}=4.1, \mathrm{p}<0.041, \mathrm{df}=1\right)$. Factors not statistically significant were the site of injury on the skull, number of involved lobes, retained bone or metallic fragments, and hemorrhagic complications after surgery Table 1 .

Multivariate regression analysis revealed that GOS score $\left(\mathrm{X}^{2}=35.24, \mathrm{p}<0.0001, \mathrm{df}=1\right)$ and residual deficit $\left(X^{2}=7.1033, p<0.0077, d f=1\right)$ (Table 2$)$ were the only significant factors predicting PTE.

\section{DISCUSSION}

The pathogenesis of late-onset seizures (beyond the 1st week postinjury) as a consequence of penetrating head injury, remains unsolved. In numerous studies the authors have carefully investigated its incidence, $, 1,2,4,6,11,20,25,28$ onset latency, $4,6,7,10,19,20,23,26,28$ persistence, ${ }^{6,7,15,20,24,26,28}$ frequency, ${ }^{20,26}$ type,${ }^{20}$ and cessation. ${ }^{6,7,20}$ Considering a variety of confounding risk factors, Feeny and Walker, ${ }^{10}$ and Weiss and associates, ${ }^{29}$ and others ${ }^{18}$ were able to devise formulas with which to predict onset latency with great accuracy. The incidence of late-onset PTE and onset latency in different military campaigns has remained remarkably constant. ${ }^{16,19,20}$ Among independent variables certain characteristics of the wound profile, clinical condition, and outcome status of the patient may play pivotal roles in predisposing a patient to PTE. Less clear is the relation of these confounding variables with seizure onset while considered in a multivariate analysis.

\section{Wound Profile}

Site. Since the introduction of computerized tomography, it has been much easier to determine the exact geometrical and dynamic characteristics of the wound profile. The site of injury on the skull is a crude estimation of the extent of injury to the brain itself; the latter is dependent on the degree of the loaded kinetic energy and penetration. Site of injury near the Rolandic region was a significant risk factor in the series reported by Gliddon. ${ }^{11}$ Parietal, temporal, and frontal areas were quite conspicuous in three major series reported by Adeloye and Odeku, ${ }^{2}$ Ascroft, ${ }^{4}$ and Caveness, et al. ${ }^{6}$ Feeney and Walker ${ }^{10}$ in their probability formula of seizure occurrence, placed significant value on the lesions inflicted on centroparietal area. In the Iranian cohort, site did not gain statistical value as a significant factor in uni- or multivariate analysis (Table 1).
Mode. In the series reported by Weiss and Caveness, ${ }^{26}$ they found no relationship between the mode of injury and seizure occurrence. Tangential and through-and-through injuries in the report by Adeloye and Odeku ${ }^{2}$ were contributing risk factors in PTE. Univariate analysis of the casualties from the Iran-Iraq War indicated a significant relationship between mode of injury and incidence of PTE $\left(X^{2}=10.731, p<0.5, d f=5\right)$; however, when corrected for other variables, the mode of injury lost its significance (Tables 1 and 2).

Transventricular Injuries. Weiss and Caveness ${ }^{26}$ noted a high fit rate in deep lesions and those penetrating the ventricular system. Nearly $41 \%$ of the patients with ventricular penetration eventually developed PTE $\left(\mathrm{X}^{2}=6.981, \mathrm{p}<\right.$ $0.008, \mathrm{df}=1$ ). Although penetration of the ventricular system is a significant risk factor, it loses its significance when analyzed in a multivariate fashion with other confounding variables (Table 1).

Number of Involved Lobes. Weiss and coworkers ${ }^{28}$ incorporated the degree of lobar involvement in their predictive formula of seizure occurrence. This could be an indication of the degree of brain loss, which was significant in the study of Salazar, et al. ${ }^{20}$ In the Iranian cohort, the number of lobes did not achieve significance when evaluated in a univariate fashion (Table 1).

Retained Bone or Metal Fragment. In the series reported by Gliddon, ${ }^{10}$ the presence of retained bone fragments increased chances of PTE. Whereas the incidence of PTE in Gliddon's series was $18.9 \%$, almost $67 \%$ of the patients with retained bone fragments became epileptic. In more recent studies the investigators have failed to demonstrate a significant relationship between retained bone and the occurrence of late epilepsy. ${ }^{19,20,29}$ Posttraumatic epilepsy was not found to have a statistical relationship with retained bone fragments in our study. Ascroft, ${ }^{4}$ studying casualty cases from World War I, noted that victims whose metal fragments were surgically removed had a higher chance of developing epilepsy. Fifty-three percent of the patients whose fragments were surgically removed developed PTE, as compared with $38 \%$ of those in whom fragments were left intact. The incidence of PTE in that series was $45 \% .{ }^{4}$ Salazar et al., ${ }^{20}$ noted an increased chance of late-onset seizures in patients with retained metal fragments $(p<0.02)$. In the present study, neither retention of bone nor metal fragments was instrumental in causing late-onset seizures.

Intracranial Hematomas. Intracranial hematomas are of special interest in both closed and penetrating head injury, as is the role they play as risk factors for late epileptogenic attacks. ${ }^{3,20}$ The biochemical relationship of heme and iron in the pathogenesis of PTE may be significant. ${ }^{9,13,14,17} \mathrm{Sa}-$ lazar, et al., ${ }^{20}$ studying patients in the Vietnam Head Injury Study, found a significant relationship $(p<0.01)$ between intracerebral hematomas and seizure occurrence. The duration of seizure was also increased in patients with intracranial hematomas. Intracranial hematomas were not shown to have any statistical significance in our study.

\section{Clinical Status of the Patients}

Early Seizures. Seizures occurring within the 1st week after head trauma are designated as early seizures, and 
B. Aarabi, et al.

TABLE 1

RESULTS OF UNIVARIATE ANALYSIS OF CONFOUNDING FACTORS INFLUENCING THE INCIDENCE OF POSTTRAUMATIC EPILEPSY IN 489 PATIENTS WITH MISSILE HEAD WOUNDS WHO WERE FOLLOWED FOR 6 TO 154 MONTHS*

\begin{tabular}{|c|c|c|c|c|c|}
\hline Variable & DF & $\begin{array}{c}\text { Percent } \\
\text { w/ Seizure }\end{array}$ & $\begin{array}{l}\text { Chi- } \\
\text { Square }\end{array}$ & Value & $\begin{array}{l}\text { Signi- } \\
\text { ficance }\end{array}$ \\
\hline site of injury & 5 & & 4.017 & 0.547 & NS \\
\hline frontal & & 33.33 & & & \\
\hline parietal & & 34.76 & & & \\
\hline temporal & & 34.48 & & & \\
\hline occipital & & 18.75 & & & \\
\hline parietofrontal & & 32.26 & & & \\
\hline mode of injury & 5 & & 10.731 & 0.057 & $\mathrm{~s}$ \\
\hline perforating & & 40.63 & & & \\
\hline penetrating (crossed) & & 41.56 & & & \\
\hline penetrating (uncrossed) & & 30.43 & & & \\
\hline tangential & & 24.22 & & & \\
\hline GCS score & 3 & & 19.489 & 0.0001 & $\mathrm{~S}$ \\
\hline $3-5$ & & 70 & & & \\
\hline $6-8$ & & 37.5 & & & \\
\hline $9-12$ & & 41.18 & & & \\
\hline $13-15$ & & 27.70 & & & \\
\hline motor/admission & 1 & 39.63 & 11.796 & 0.001 & S \\
\hline dysphasia & 1 & 50.00 & 5.323 & 0.021 & $\mathrm{~s}$ \\
\hline intracerebral hematoma & 1 & 46.67 & 3.108 & 0.07 & NS \\
\hline infection & 1 & 48.72 & 5.365 & 0.021 & $\mathrm{~S}$ \\
\hline early seizure & 1 & 50.00 & 4.184 & 0.041 & $\mathrm{~S}$ \\
\hline GOS score & 2 & & 76.494 & 0.0001 & $\mathrm{~S}$ \\
\hline 5 & & 7.43 & & & \\
\hline 4 & & 46.34 & & & \\
\hline 3 & & 40.74 & & & \\
\hline retained bone & 1 & 40.37 & 2.905 & 0.088 & NS \\
\hline retained fragment & 1 & 34.00 & 0.317 & 0.573 & NS \\
\hline No. of lobes & 4 & & 5.718 & 0.221 & NS \\
\hline 1 & & 30.13 & & & \\
\hline 2 & & 31.82 & & & \\
\hline 3 & & 48.57 & & & \\
\hline transventricular injury & 1 & 41.75 & 6.981 & 0.008 & S \\
\hline motor deficit FU & 1 & 38.58 & 5.963 & 0.015 & S \\
\hline
\end{tabular}

${ }^{*} \mathrm{FU}=$ follow up; NS = not significant; $\mathrm{S}$ = significant.

their incidence ranges from 2.2 to $8.9 \% .^{4,15,18,20,29}$ Annegers, et al., ${ }^{3}$ in a population study of closed head injury found a significant univariate relationship between early seizures and subsequent late-onset epilepsy, but this significance was lost when results were analyzed in a multivariate model. Weiss and Feeney ${ }^{28}$ found that $36(75 \%)$ of 48 patients in their series with early seizures developed late-onset PTE. In our study, early-onset seizures were significantly associated with late-onset epilepsy in a univariate analysis $(\mathrm{p}<0.04)$. This significance, however, lost its value when corrected for other confounding variables. In several series early-onset seizures were not shown to be associated with late-onset seizures. ${ }^{7,18,20}$

Level of Consciousness. Significant value has been placed on a patient's level of consciousness at the time of admission and late convulsions. ${ }^{1,3,6,7,10,20,26,29}$ In the present study, admission GCS score was significantly associated with late-onset epilepsy. Almost 70\% of the patients with an admission GCS score of 3 to 5 became epileptic, as compared to $27.7 \%$ of patients with GCS scores of 13 to $15\left(X^{2}=19.489, p<0.0001, d f=3\right)$. When corrected for other variables, the statistical significance of level of consciousness was lost (Tables 1 and 2).

Focal Deficit. Motor and speech deficits have been shown to be significant risk factors in major military conflicts of the 20th century. ${ }^{1,6,10,15,19,20,29}$ Residual motor deficit was one of two significant confounding variable in uni- and multivariate analysis in the Iranian cohort (univariate analysis: $\mathrm{X}^{2}=5.963 \mathrm{p}<0.015$; multivariate $\mathrm{X}^{2}=$ $7.1, \mathrm{p}<0.007$ ) (Tables 1 and 2).

Glasgow Outcome Scale Score. The GOS score obtained after a penetrating head injury is perhaps the most significant predictor of late-onset epilepsy and is significant in both uni- or multivariate analysis. Almost 40 to $46 \%$ of patients with moderate to severe disability became epilep- 
TABLE 2

RESULTS OF MULTIVARIATE REGRESSION ANALYSIS OF VARIABLES INFLUENCING THE INCIDENCE OF POSTTRAUMATIC EPILEPSY IN 489 PATIENTS WITH MISSILE HEAD WOUNDS WHO WERE FOLLOWED FOR 6 TO 154 MONTHS*

\begin{tabular}{lcccc}
\hline \multicolumn{1}{c}{ Variable } & DF & Chi-Square & p Value & Significance \\
\hline frontal & 1 & 3.1982 & 0.07 & $\mathrm{NS}$ \\
parietal & 1 & 2.8998 & 0.0886 & $\mathrm{NS}$ \\
temporal & 1 & 0.8587 & 0.3541 & $\mathrm{NS}$ \\
parietofrontal & 1 & 1.3473 & 0.2458 & $\mathrm{NS}$ \\
perforating mode & 1 & 0.2575 & 0.6118 & $\mathrm{NS}$ \\
penetrating (crossed) & 1 & 2.2778 & 0.1312 & $\mathrm{NS}$ \\
penetrating (uncrossed) & 1 & 0.2684 & 0.6044 & $\mathrm{NS}$ \\
GCS score & 1 & 2.4262 & 0.1193 & $\mathrm{NS}$ \\
motor deficit (admission) & 1 & 1.3432 & 0.2465 & $\mathrm{NS}$ \\
dysphasia & 1 & 2.8439 & 0.0917 & $\mathrm{NS}$ \\
ICH & 1 & 1.3742 & 0.2411 & $\mathrm{NS}$ \\
infection & 1 & 1.2729 & 0.2592 & $\mathrm{NS}$ \\
transventricular & 1 & 0.5243 & 0.4699 & $\mathrm{NS}$ \\
retained bone & 1 & 0.3525 & 0.5527 & $\mathrm{NS}$ \\
early seizure & 1 & 2.4498 & 0.1175 & $\mathrm{NS}$ \\
No. of lobes & 1 & 0.9136 & 0.3392 & $\mathrm{NS}$ \\
GOS score & 1 & 35.2425 & 0.0001 & $\mathrm{~S}$ \\
motor deficit at FU & 1 & 7.1033 & 0.0077 & $\mathrm{~S}$ \\
\hline
\end{tabular}

${ }^{*} \mathrm{FU}=$ follow up; $\mathrm{ICH}=$ intracranial hematoma.

tic as compared with $7.4 \%$ of the patients with no or mild deficit (univariate analysis $\mathrm{X}^{2}=76.494, \mathrm{p}<0.0001, \mathrm{DF}=$ 2; multivariate analysis, $\mathrm{p}<0.0001$ ) (Tables 1 and 2).

\section{Intracranial Sepsis}

Ascroft ${ }^{4}$ realized that seizures were twice as common in World War I patients whose wounds became complicated with infection, and the results of other studies seem to bear out this contention. ${ }^{1,4,10,26}$ Brain abscess was not associated with increased incidence of PTE in the Vietnam Head Injury Study reported by Salazar, et al. ${ }^{19}$ In a group of 200 patients who were followed for at least 36 months, Aarabi, et al., found a PTE rate of $68.4 \%$ in patients who developed infectious complications. In the present series, almost $48.7 \%$ of the patients with intracranial sepsis developed late-onset epilepsy. When evaluated as single variable, infectious complications were associated with an increased rate of late PTE $\left(\mathrm{X}^{2}=5.365, \mathrm{p}<0.02\right)$. However, this significance was lost when the data were analyzed in a multivariate fashion.

\section{CONCLUSIONS}

Analysis of variables contributing to posttraumatic epilepsy helps us better understand the pathogenesis and therefore focus on judicious use of medications to control this major disability following penetrating head injury. Thirty-two percent of the present cohort became epileptic during a follow-up period ranging from 6 to 154 months. Variables such as type of projectile injury, site of injury on the skull, age, number of lobes affected, hemorrhagic complications, and retained metallic or bone fragments had no effect on the occurrence of unprovoked PTE.
Although GOS score, admission GOS score, motor deficit, mode, transventricular injury, dysphasia, central nervous infections, and early seizures were important contributing factors in a univariate model, multivariate analysis indicated GOS score and motor deficit to be of particular significance in the genesis of late PTE.

\section{Acknowledgments}

The authors would like to thank Sandra Benson for editorial assistance and Dale Mondy for statistical analysis of the data.

\section{References}

1. Aarabi B, Alibaii, E, et al: Posttraumatic epilepsy. J Neurosurg 84:370A, 1996 (Abstract)

2. Adeloye A, Odeku EL: Epilepsy after missile wounds of the head. J Neurol Neurosurg Psychiatry 34:98-103, 1971

3. Annegers JF, Houser WA, Coan SP, et al: A population-based study of seizures after traumatic brain injuries. N Engl J Med 338:20-24, 1998

4. Ascroft PB: Traumatic epilepsy after gunshot wounds of the head. Br Med J 1:739-744, 1941

5. Carey ME, Young HF, and Mathis JL: The neurosurgical treatment of craniocerebral missile wounds in Vietnam. Surg Gyn Obstet 135:386-390, 1972

6. Caveness WF: Onset and cessation of fits following craniocerebral trauma. J Neurosurg 20:570-583, 1963

7. Caveness WF, Meirowsky AM, Rish BL, et al: The nature of posttraumatic epilepsy. J Neurosurg 50:545-553, 1979

8. Corkin S, Sullivan EV, Carr FA: Prognostic factors for life expectancy after penetrating head injury. Arch Neurol 41: 975-977, 1984

9. Dakin KA, Weaver DF: Mechanisms of post-traumatic seizures: a quantum pharmacological analysis of the molecular properties of an epileptogenic focus following iron-induced membrane peroxidation. Seizure 2:21-33, 1993 
10. Feeney DM, Walker AE: The prediction of posttraumatic epilepsy. A mathematical approach. Arch Neurol 36:8-12, 1979

11. Gliddon WO: Gunshot wounds of the head (a review of the after-effects in 500 Canadian Pensioners from the Great War, 1914-1918). Can Med Assoc J 49:373-377, 1943

12. Glotzner FL, Haubitz I, Miltner F, et al: [Seizure prevention using carbamazepine following severe brain injuries.] Neurochirurgia 26:66-79, 1983 (Ger)

13. Hauser WA: Prevention of post-traumatic epilepsy. N Engl J Med 323:540-541, 1990

14. Janjua NA, Mori A, Hiramatsu M: Increased aspartic acid release from the iron-induced epileptogenic focus. Epilepsy Res 6:215-220, 1990

15. Jennett B: Epilepsy After Non-Missile Head Injuries, ed 2. Chicago: Year Book Medical, 1975

16. Meirowsky AM: Notes on posttraumatic epilepsy in missile wounds of the brain. Mil Med 147:632-634, 1982

17. Mori A, Hiramatsu M, Yokoi I, et al: Biochemical pathogenesis of post-traumatic epilepsy. Pavlov J Biol Sci 25:54-62, 1990

18. Rish BL, Caveness WF: Relation of prophylactic medication to the occurrence of early seizures following craniocerebral trauma. J Neurosurg 38:155-158, 1973

19. Salazar AM, Aarabi B, Levi L, et al: Posttraumatic epilepsy following craniocerebral missile wounds in recent armed conflicts, in Aarabi B, Kaufman HH, Dagi TF, et al (eds): Missile Wounds of the Head and Neck. Park Ridge, IL: American Association of Neurological Surgeons, Vol 2, 1999, pp 281-292

20. Salazar AM, Jabbari B, Vance SC, et al: Epilepsy after penetrating head injury. I. Clinical correlates: a report of the Vietnam Head Injury Study. Neurology 35:1406-1414, 1985

21. Swanson SJ, Rao SM, Grafman J, et al: The relationship between seizure subtype and interictal personality. Results from the Vietnam Head Injury Study. Brain 118:91-103, 1995

22. Temkin NR, Dikmen SS, Anderson GD, et al: Valproate therapy for prevention of posttraumatic seizures: a randomized trial. J Neurosurg 91:593-600, 1999
23. Vespa PM, Nuwer MR, Nenov V, et al: Increased incidence and impact of nonconvulsive and convulsive seizures after traumatic brain injury as detected by continuous electroencephalographic monitoring. J Neurosurg 91:750-760, 1999

24. Walker AE: Prognosis in post-traumatic epilepsy; a 10-year follow-up of craniocerebral injuries of World War II. JAMA 164: 1636-1641, 1957

25. Watson CW: Incidence of epilepsy following craniocerebral injury. II. Three-year follow-up study. Arch Neurol Psychiatry 68:831-834, 1952

26. Weiss GH, Caveness WF: Prognostic factors in the persistence of posttraumatic epilepsy. J Neurosurg 37:164-169, 1972

27. Weiss GH, Caveness WF, Einsiedel-Lechtape H, et al: Life expectancy and causes of death in a group of head-injured veterans of World War I. Arch Neurol 39:741-743, 1982

28. Weiss GH, Feeney DM, Caveness WF, et al: Prognostic factors for the occurrence of posttraumatic epilepsy. Arch Neurol 40: $7-10,1983$

29. Weiss GH, Salazar AM, Vance SC, et al: Predicting posttraumatic epilepsy in penetrating head injury. Arch Neurol 43: 771-773, 1986

30. Young B, Rapp RP, Norton JA, et al: Failure of prophylactically administered phenytoin to prevent late posttraumatic seizures. J Neurosurg 58:236-241, 1983

Manuscript received December 1, 1999.

Accepted in final form December 15, 1999.

Part of this paper was presented at the Annual Meeting of the American Association of Neurological Surgeons, April 26--May 3, 1996, Minneapolis, Minnesota. Portions of the data have been reported in a book chapter by Salazar, et al. ${ }^{19}$

Address reprint requests to: Bizhan Aarabi, M.D., Division of Neurosurgery, University of Nebraska Medical Center, 982035 NMC, Omaha, Nebraska 68198-2035. email: BAARABI@MSN.COM. 